\title{
Propuesta pragmático-discursiva para analizar artículos editoriales: modelo y estrategias
}

\author{
Miguel Alcíbar Cuello \\ jalcibar@us.es \\ Universidad de Sevilla
}

Recibido: 17 de febrero de 2014

Aceptado: 10 de septiembre de 2014

\begin{abstract}
Resumen
En este artículo se propone un procedimiento pragmático-discursivo para analizar editoriales, basado en la clasificación de los editoriales, según sus modos argumentativos y sus formas expresivas, así como en el Análisis del Discurso y la teoría del framing. El método permite, por una parte, indagar acerca de cómo la ideología del medio condiciona la manera de encuadrar los acontecimientos y, por otra parte, de cómo el periódico, en ocasiones, se apropia de conocimiento experto para defender (o atacar) ciertos postulados socio-políticos. Así, se revelan las estrategias discursivas puestas en juego para encuadrar los problemas de una determinada manera. Para ilustrar las bondades del procedimiento, la última parte del artículo se centra en el análisis pormenorizado de un editorial.
\end{abstract}

Palabras clave: editoriales, análisis del discurso, framing, argumentación.

\section{Pragmatic-discursive proposal to analyse newspaper editorials: model and strategies}

\begin{abstract}
This paper presents a general discursive and pragmatic procedure for analyzing editorials. This proposal is based on the editorials' classification according to its argumentative modes and its expressive forms as well as Discourse Analysis and Framing Theory. This method allows one to enquire how media's ideology determines the way of framing the events and how the expert knowledge is appropriated by newspapers in order to defend (or attack) certain socio-political claims. In this way, the discursive strategies in play to frame the issues in a specific way are unfolded. The latter part of the paper is focused on a detailed analysis of one editorial, in order to provide examples the virtues of the model.
\end{abstract}

Keywords: Newspaper editorials, discourse analysis, framing, argumentation.

\section{Referencia normalizada}

ALCÍBAR CUELLO, Miguel (2015): "Propuesta pragmático-discursiva para analizar artículos editoriales: modelo y estrategias". Estudios sobre el Mensaje Periodístico. Vol. 21, Núm. 1 (enero-junio), págs.: 225-241. Madrid, Servicio de Publicaciones de la Universidad Complutense.

Sumario: 1. Introducción. 2. El editorial, la voz institucional del periódico. 3. Fundamentos epistemológicos y metodología de estudio; 3.1. Análisis del discurso; 3.2. Teoría del encuadre. 4. Descripción del procedimiento pragmático-discursivo para el análisis de editoriales; 4.1. Lectura atenta y comprensiva: contextualización; 4.2. Formulación de la tesis; 4.3. Estudio de los mecanismos argumentativos; 4.4. Identificación y justificación de la tipología del editorial y del juicio principal del epílogo; 4.5. Análisis del framing; 4.6. Identificación y justificación de la ideología del medio; 4.7. Valoración general y otros datos complementarios de interés. 5. Análisis pragmático-discursivo del editorial "Libro abierto"; 5.1. Lectura atenta y comprensiva: contextualización; 5.2. Formulación de la tesis; 5.3. Estudio de los mecanismos argumentativos; 5.4. Identificación y justificación de la tipología del editorial y del juicio principal del epílogo; 5.6. Análisis del framing; 5.7. Identificación y justificación de la ideología del medio; 5.8. Valoración general y otros datos complementarios de interés. 6. Conclusiones. 7. Referencias bibliográficas. 8. Anexo: texto del editorial. 


\section{Introducción}

En las sociedades plurales los medios de comunicación influyen sobre la opinión pública encuadrando de modo disímil los acontecimientos de interés social. El editorial es el género periodístico de opinión por medio del cual el periódico examina, evalúa y enjuicia la información de actualidad que atañe a los ciudadanos, incluidos políticos y legisladores. A pesar de este papel crucial, todavía no se ha abordado en profundidad (salvo algún honroso intento) el diseño sistemático de un procedimiento para analizar editoriales desde una perspectiva pragmática y discursiva.

Uno de esos intentos es la propuesta de Luisa Santamaría (Santamaría, 1997: 164167; Santamaría y Casals, 2000: 368-372). Basándose en su experiencia docente, la autora elaboró un método didáctico para afrontar el análisis de editoriales de una manera razonada. Según Santamaría, la tesis (opinión con contenido intelectual) y la argumentación (cadena de razonamientos que sirven para sustentar la tesis expuesta) son los elementos clave de todo editorial. Así, el análisis textual es el que permite descomponer el texto en sus distintas partes con objeto de entender las estrategias de su composición y desentrañar las intenciones que lo animan.

Tomando como referencia este trabajo seminal, se presenta aquí un procedimiento de análisis que, además de permitir que el analista pueda decodificar y comprender el contenido explícito del mensaje, también lo provea de una serie de herramientas para que pueda establecer relaciones, no siempre palmarias, entre texto y contexto, identificar y analizar la estructura compositiva y los recursos retóricos del editorial, y, en última instancia, sintetizar su sentido global. La exploración de textos argumentativos suele ser una tarea dificultosa para los alumnos de periodismo y otras áreas de ciencias de la comunicación, por lo que desarrollos pragmáticos como este cobran especial relevancia.

La propuesta que aquí se expone es un método pragmático-discursivo para el análisis de editoriales, basado en la experiencia docente del autor; se cimenta sobre la clasificación de editoriales según sus modos argumentativos y sus formas expresivas (Santamaría, 1997: 164-167; Santamaría y Casals, 2000: 273-277), así como en los presupuestos del Análisis del Discurso (AD) (Fairclough y Wodak, 2000: 367-404; Van Dijk, 2000a: 21-65; Van Dijk, 2000b: 19-64) y de la teoría del framing (Gamson y Modigliani, 1989; Entman, 1993; Tankard, 2001; Brossard, 2010; Sádaba, 2008).

\section{El editorial, la voz institucional del periódico}

El artículo editorial es un género de opinión por medio del cual el periódico como institución social enjuicia aquellos acontecimientos de la actualidad que considera relevantes desde un punto de vista social, político, económico o cultural. Es, por tanto, el tipo textual por el que la empresa periodística juzga, a partir de su propia perspectiva ideológica, las noticias de trascendencia social. Según Martínez Albertos el editorial es el "artículo periodístico sin firma que explica, valora y juzga un hecho noticioso de especial importancia. Este juicio colectivo e institucional se formula de acuerdo con una convicción de orden superior que refleja la postura ideológica de cada periódico." (Cfr. Santamaría y Casals, 2000: 267). Su estudio tiene especial interés cuando queremos dilucidar las principales posturas en torno a los debates públicos, puesto que los edito- 
riales son expresiones claras del posicionamiento ideológico de los propietarios y gestores de los periódicos (Henry y Tator, 2002). No en vano los editoriales desempeñan un importante papel en modelar la opinión pública (Le, 2009).

Del periodismo norteamericano proviene la exposición clásica de las cuatro funciones básicas que pueden exhibir los editoriales (Cfr. Santamaría, 1997: 65; Santamaría y Casals, 2000: 267-268), a saber:

1. Formular juicios: esta es la razón de ser del editorial. El equipo editorialista forma un cuerpo social legitimado por su prestigio profesional que lo convierte en una especie de "conciencia pública". Al periódico no se le presupone neutralidad en los debates o controversias, pero sí una clara y rigurosa interpretación de los acontecimientos desde su particular visión de éstos. Por tanto, la función básica del editorial es la de juzgar, orientando al lector en la interpretación de los hechos. Estos juicios, que suponen nueva información, son sobre pretensiones de realidad y sobre valores asociados a estas pretensiones. Se genera así la polémica social, siempre deseable en una sociedad cívica, plural y tolerante.

2. Explicar los hechos: el equipo editorialista puede explicar al lector la naturaleza de los acontecimientos de actualidad y su relevancia social, desde la perspectiva que crea más conveniente. Por tanto, se aportan explicaciones para contextualizar los hechos de referencia que se están valorando y así hacerlos accesibles al lector. Es importante distinguir entre exponer y explicar. Exponer equivale a "informar", es decir, transmitir datos con un alto grado de organización y jerarquización, mientras que explicar es la actividad que, partiendo de una base expositiva necesariamente existente, se realiza con una clara vocación didáctica, puesto que su finalidad es hacer accesibles para el lector determinados conocimientos que se presuponen difíciles de aprehender (Bassols y Torrent, 2003: 71).

3. Dar antecedentes: la interpretación ideológica de la información de actualidad requiere manejar tramas argumentativas de naturaleza histórica, política, social, económica o cultural que sitúe el objeto de opinión dentro de un contexto espacio-temporal y cognoscitivo comprensible para el lector. El equipo editorialista recurrirá entonces a aportar la documentación necesaria para que sus opiniones no parezcan gratuitas, sino el resultado reflexivo y riguroso de un proceso de argumentación.

4. Predecir el futuro: sobre la base del análisis de la situación, esto es, de antecedentes y consecuentes, algunos editoriales se escriben para vaticinar resultados de tipo político, económico o social. En este sentido, la experiencia de otras situaciones similares se toma como fundamento de estas proyecciones de futuro. La predicción ha de seguir un proceso de razonamiento lógico, so pena de caer en el dogmatismo.

Según sus modos argumentativos y expresivos, Santamaría y Casals (2000: 273277) han establecido una categorización coherente de ocho tipos de editoriales, que es muy útil para el análisis que nos concierne. En esta clasificación se pueden diferenciar dos grandes grupos. Al primer grupo lo llamaremos editoriales-AS y lo forman aquellos editoriales en los que se realiza un análisis de la situación (AS), esto es, un análisis de antecedentes (causas en forma de ejemplos históricos significativos, datos estadísticos, sociológicos, científicos, etc., que ayudan al lector a entender por qué se ha llegado a la situación actual que se está enjuiciando) y de consecuentes (efectos en 
forma de plausibles escenarios futuros, proyecciones, prospectivas, etc., que permiten al lector valorar las posibles consecuencias de la situación). A este grupo pertenecen los tipos analítico o expositivo, explicativo, predictivo, admonitorio y crítico. El segundo grupo, que llamaremos editoriales-NoAS, lo integran aquellos editoriales cuya argumentación emana de unas determinadas creencias tácitas y de una estricta jerarquía de valores, y no tanto de un análisis ponderado de causas y efectos. En él se incluyen los tipos combativo, apologético y de diatriba.

Por lo general, un editorial concreto suele ser tipológicamente híbrido, es decir, es una combinación de dos o, incluso, tres tipos. Pero no todos los híbridos son viables. La jerarquía de predominancia y la viabilidad de ciertas combinaciones son atributos cardinales en el estudio de los editoriales. Así, por ejemplo, diremos que un editorial concreto es admonitorio con un componente crítico, si predomina en él el tipo admonitorio y tiene como tipo subsidiario el crítico. Este híbrido es viable porque sus respectivos rasgos no entran en contradicción. Sin embargo, no es posible hibridar sin caer en paradoja un tipo del grupo de editoriales-AS con otro del grupo de editoriales-NoAS. Por consiguiente, en el proceso de análisis es clave determinar si los argumentos que se manejan se derivan de un ponderado análisis de la situación o, por el contrario, se apoyan en creencias o en una efectista retórica de las emociones.

\section{Fundamentos epistemológicos y metodología de estudio}

\subsection{Análisis del discurso}

El AD engloba una amplia variedad de diferentes perspectivas para el estudio de textos, que tienen en común el rechazo a la noción realista de que el lenguaje es simplemente un medio neutral para reflejar o describir el mundo y el énfasis en el papel central que desempeña el discurso en la construcción de la vida social.

El AD es un método cualitativo, interpretativo y construccionista que incorpora tanto un conjunto de técnicas para analizar textos de una manera estructurada, como un conjunto de asunciones sobre los efectos constructivos del lenguaje. Trata de indagar en cómo los hechos, ideas, pretensiones de conocimiento y argumentos, se producen y se sostienen socialmente (Hardy, 2001; Phillips y Hardy, 2002). El AD admite que es imposible excluir el discurso de su contexto de producción/interpretación más amplio (Fairclough, 1995; Van Dijk, 1997; Van Dijk, 2009). Como señala Hardy:

"[The meanings of any discourse are] created, supported, and contested through the

production, dissemination, and consumption of texts; and emanate from interactions between the social groups and the complex societal structures in which the discourse is embedded" (Hardy, 2001: 28).

En definitiva, para el AD los discursos son cuerpos de textos interrelacionados, esto es, un sistema concreto de textos en el sentido de que generan una realidad material mediante las prácticas sociales que invocan (Van Dijk, 200b: 24-26).

\subsection{Teoría del encuadre}

En investigación en comunicación, el encuadre (frame) es una idea central que organiza, jerarquiza y proporciona sentido a un asunto o problema, de tal forma que los 
miembros de una audiencia pueden interpretarla (Gamson y Modigliani, 1989: 3; Brossard, 2010: 310-313). Así, encuadrar (framing) es el acto de enfatizar ciertos aspectos (y minimizar otros) de un acontecimiento para permitir la interpretación y contextualización de la información, haciendo más comprensible ésta para la audiencia (Entman, 2004: 5). En otras palabras, encuadrar es definir ciertos asuntos -en general, por las élites- para su consumo público, y diseminar estas definiciones mediante el uso de los medios de comunicación de masas (Berinsky y Kinder, 2006: 640). En el ámbito de los estudios de comunicación, la definición de framing postulada por Entman es la que más éxito ha tenido:

"To frame is to select some aspects of a perceived reality and make them more salient in a communicating text in such a way as to promote a particular problem, definition, causal interpretation, moral evaluation, and/or treatment recommendation for the item described" (Entman, 1993: 52).

En efecto, los encuadres definen problemas -determinan lo que un agente causal hace con qué costes y beneficios, por lo general medidos éstos en términos de valores culturales comunes; diagnostican causas -identifican las fuerzas que originan el problema; hacen juicios morales -evalúan a agentes causales y sus efectos; y sugieren remediosofrecen y justifican tratamientos para el problema y predicen sus efectos probables.

El enmarcado mediático opera, como mínimo, a cuatro niveles diferentes: al nivel del contenido (media content), de la producción (production), de los encuadres de la audiencia (audience frames) y de la cultura general (general culture) (Dahinden, 2002: 186).

Con respecto al enmarcado a nivel del contenido, hay autores que distinguen entre encuadres genéricos (aquellos que pueden identificarse en relación a diferentes temas, son diacrónicos y funcionan para distintos contextos culturales) y encuadres específicos (aquellos que sólo son pertinentes para temas específicos) (de Vreese, Peter y Semetko, 2001: 108-110; Sádaba, 2008). El procedimiento que se propone adopta de manera genérica la clasificación de encuadres periodísticos recogida por Neuman, Just y Crigler (1992).

Varios son los autores que han estudiado los múltiples recursos que contribuyen a los encuadres noticiosos. En general, estos frames se pueden identificar en los relatos periodísticos mediante el análisis de palabras clave, metáforas, conceptos, símbolos, ejemplos de naturaleza histórica de los que se extraen lecciones, muletillas, frases de moda, eslóganes, descripciones verbales significativas, imaginería visual, entre otros (Gamson y Modigliani, 1989: 2-4; Entman, 1991: 7; Shah et al., 2002: 367). Además de estos dispositivos de encuadre (framing devices), en terminología de Gamson y Modigliani, también cabe analizar lo que estos mismos autores denominan dispositivos de razonamiento (reasoning devices), esto es, antecedentes (análisis de las causas), consecuentes (análisis de los efectos) y principios (conjunto de demandas morales). Por su parte, Tankard (2001: 101) sugiere una lista más exhaustiva de mecanismos de encuadre periodísticos, a saber: titulares; subtítulos; fotografías; pies de fotos; entradillas; selección de fuentes; selección de citas; entrecomillados enfáticos; logos; estadísticas, tablas y gráficos; conclusiones (declaraciones, párrafos de clausura). 
En síntesis, se pueden identificar encuadres periodísticos al analizar sus palabras clave, el uso de metáforas, la imaginería visual, los patrones descriptivos, el argumentario, etc.

\section{Descripción del procedimiento pragmático-discursivo para el análisis de edi- toriales}

El procedimiento es secuencial, consta de siete etapas bien diferenciadas, no independientes, y permite que el analista, mediante un juego dialéctico de preguntas-respuestas, alcance un análisis razonado y razonable de editoriales. El protocolo de actuación es el siguiente:

\subsection{Lectura atenta y comprensiva: contextualización}

Con esta primera lectura se debe ser capaz de comprender no sólo el contenido cognoscitivo del editorial, sino sobre todo los vínculos más notables entre texto y contexto (identificar la información de actualidad que nutre al editorial, o contextualización informativa, y relacionar elementos extra-textuales, como la fecha de publicación del editorial o el ámbito de tirada del periódico, con el contexto social, económico y político más amplio, o contextualización socio-política).

Es aconsejable que el analista enumere las líneas del editorial de 5 en 5 y que subraye todos aquellos términos o expresiones que tienen "carga valorativa" (v. g., adjetivos calificativos, metáforas y otras figuras retóricas). Este subrayado valorativo será de gran ayuda más adelante cuando haya que justificar el tipo o tipos de editorial. La carga valorativa debe observarse en un sentido cuantitativo (número total de términos o expresiones valorativas), y en un sentido cualitativo (origen pragmático de esos términos y expresiones, es decir, sus significados cuando son usados socialmente).

\subsection{Formulación de la tesis}

Dado que la tesis es la postura ideológica que el periódico adopta sobre un asunto de transcendencia social, responder adecuadamente a la pregunta "¿para qué se ha escrito el editorial?" es clave para poder formularla en una frase declarativa de 3-4 líneas. Esta frase declarativa debe plasmar con precisión el núcleo de la posición adoptada por el periódico. Las partes del editorial en las que es más frecuente encontrar rastros, huellas, signos de la tesis son, sin duda, las partes más relevantes del texto, esto es, el titular y el epílogo (o parte final dedicada a las conclusiones).

\subsection{Estudio de los mecanismos argumentativos}

Esta etapa y la siguiente representan el meollo del análisis. En ellas es donde se estudian los mecanismos argumentativos, la tipología del editorial y el juicio principal del epílogo.

Con respecto a los mecanismos argumentativos, es importante indicar que para construir sus opiniones los periodistas frecuentemente emplean los siguientes tipos de argumentos: de autoridad, mediante el ejemplo, por analogía, de causalidad y deductivos (Perelman y Olbrechts-Tyteca, 1989; Santamaría y Casals, 2000: 163-264; Martínez-Costa, 2010: 37-47). 
Así, los argumentos de autoridad son los que para sustentar una opinión se basan en el conocimiento aportado por fuentes que socialmente se consideran fidedignas; los argumentos mediante el ejemplo ofrecen uno o más ejemplos significativos en apoyo de una generalización; los argumentos por analogía transponen un caso o ejemplo específico a otro, confiando en que si ambos son semejantes en muchos aspectos, también lo serán en el aspecto concreto que se compara; los argumentos de causalidad correlacionan el estado de un fenómeno con sus causas; los argumentos deductivos, quizá los menos empleados por los periodistas, son aquellos que adoptan una estructura cuasilógica en los que la verdad de sus premisas garantiza la verdad de sus conclusiones.

\subsection{Identificación y justificación de la tipología del editorial y del juicio princi- pal del epílogo}

Tipología del editorial: Se debe justificar el tipo (o tipos, si es híbrido) de editorial que impera(n) en el texto (v. epígrafe 2). Cabe señalar que, en el caso de editoriales híbridos, es necesario determinar el tipo principal y el subsidiario. Para fijar el tipo predominante es preciso observar la tesis, pues mantienen entre sí un estrecho vínculo.

Para determinar la tipología del editorial que tenemos entre manos se aconseja plantearse la siguiente pregunta: “¿Hace o no hace el editorial un análisis de la situación?" Responderla es crucial, puesto que determina si el editorial analizado pertenece al grupo de los editoriales AS o No-AS y, por tanto, establece las condiciones de hibridación en caso de que la tipología del editorial sea múltiple. Además de los rasgos comunes que comparte con los otros de su grupo de afinidad, cada tipo presenta otros que le son específicos. Se trata, pues, de localizar en el texto cómo se materializan esos rasgos específicos, para así poder fijar el tipo exacto (v. epígrafe 2). Los editorialesNo-AS no plantean ninguna dificultad, puesto que sus rasgos específicos son muy distintos entre sí y no cabe la hibridación entre ellos. Sin embargo, el caso de los editoriales-AS es más complejo, por lo que es pertinente que el analista se plantee una cuestión más: “¿Cómo de activada está la función expresiva?” Si atendemos a los rasgos específicos, es posible distribuir los editoriales-AS según un "gradiente de expresividad" (Fig. 1). El gradiente va del polo negativo donde está el "más frío", el analítico (AN), al polo positivo donde se ubica el "más caliente", el crítico (CR), pasando en este orden por el explicativo (EX), predictivo (PR) y admonitorio (AD):
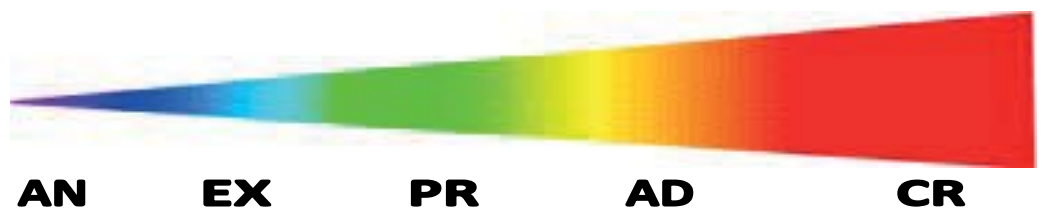

Fig. 1. Representación esquemática del "gradiente de expresividad" en los tipos de editorialesAS. Los colores fríos indican que la función expresiva está poco activa, mientras que los calientes muestran lo contrario.

Tras observar el grado de expresividad, ayudándonos del subrayado valorativo realizado en la primera fase, así como la inestimable guía de la tesis, estaremos ya en disposición de estipular con garantías el tipo principal de editorial. 
Juicio principal del epílogo: Se trata de identificar en el texto el juicio principal del epílogo y determinar de qué clase es (Santamaría y Casals, 2000: 271-273). Localizar el juicio más destacado en el epílogo es prioritario, ya que suele ser conclusivo y, por consiguiente, está correlacionado parcial o totalmente con la tesis.

\subsection{Análisis del framing}

El análisis del framing le permite al analista reconocer y valorar cómo el periódico encuadra el asunto informativo que da origen al editorial. Para los fines analíticos de esta propuesta, se consideran los encuadres generales más comunes en el discurso periodístico (v. subepígrafe 3.2).

En su estudio seminal, Neumann, Just y Crigler (1992) identificaron cuatro encuadres en la cobertura noticiosa en EE.UU sobre un amplio rango de temas, a saber:

Frame conflicto: enfatiza el conflicto entre individuos, grupos o instituciones.

Frame consecuencias económicas: presenta un suceso, problema o tema en términos de las consecuencias económicas que tendrá sobre un individuo, grupo, institución, región o país.

Frame interés humano: brinda un relato personal o un ángulo emocional para presentar un suceso, tema o problema.

Frame moralidad: se encuadra un suceso, problema o tema en el contexto de prescripciones morales, religiosas o éticas.

Trabajos posteriores (Semetko y Valkenburg, 2000: 95) incluyeron otra categoría: frame atribución de responsabilidad con el que se encuadra de tal modo que se atribuye la responsabilidad a un gobierno, a un individuo o a un grupo, al generar o resolver un problema.

\subsection{Identificación y justificación de la ideología del medio}

Alcanzada esta etapa, ya se deben tener los suficientes elementos como para colegir y justificar la ideología que ampara al editorial. La tesis proporciona valiosa información sobre la ideología.

La ideología debe entenderse como un fenómeno abarcador y no como un mero reflejo de coyunturales luchas partidistas. Si bien es cierto que, en muchos casos, determinar la ideología se reduce a constatar las adhesiones partidistas del periódico, en otras ocasiones se hace necesario considerar la ideología en un sentido más amplio.

En general, y sin entrar en detalles de filosofía política, hablaremos de ideología conservadora e ideología progresista ${ }^{1}$. El conservadurismo es más bien una meta-ideología que estructura a otras ideologías. Si se aplica a las corrientes neoliberales en economía política, la ideología conservadora aboga por mercados desregularizados, abiertos y libres. Además, asume que el papel del Estado se circunscribe a proporcionar defensa y financiar infraestructuras (política no intervencionista o de laissez faire), y a impulsar la privatización de industrias, previamente nacionalizadas o financiadas

1 Evidentemente, entre estos dos extremos, coincidentes con el asentado bipartidismo español, se pueden encontrar otras alternativas ideológicas, como, por ejemplo, la de los nacionalismos periféricos. 
con dinero público. Si se aplica a las ideologías culturales, las premisas conservadoras pueden regir dos acciones complementarias, a saber: intervención limitada del Estado en ámbitos culturales (educación, investigación, medios, religión), e intervención activa mediante una legislación dura en aquellas áreas que pueden amenazar al orden moral (valores familiares, sexualidad, multiculturalismo) (Van Dijk, 1999: 355-356). Por su parte, la ideología progresista o progresismo político suele caracterizarse como una perspectiva opuesta a la conservadora, con aspiraciones más amplias en asuntos políticos, económicos, sociales y morales. Se fundamenta sobre presupuestos filosóficos que admiten la posibilidad de progreso continuo hacia unas mejores condiciones de justicia, tanto para el individuo como para la sociedad en su conjunto. El progresismo a menudo se identifica con los valores liberales: igualdad, tolerancia, libertad, defensa del individuo y sus derechos, etc. Más específicamente, respalda fortalecer el poder del Estado y de las agencias reguladoras para controlar y denunciar cualquier abuso de poder, arbitrariedad o imprudencia que conculque los derechos ciudadanos (Fox, 2011: 1363). El progresismo aboga por un Estado del bienestar, fundado en los derechos civiles.

\subsection{Valoración general y otros datos complementarios de interés}

En este último apartado se trata de que el analista relacione de manera armónica los hallazgos encontrados en la fase previa de carácter más descriptivo. Aquí se interpreta y critica para extraer conclusiones sobre el valor intencional del editorial.

\section{Análisis pragmático-discursivo del editorial "Libro abierto"}

El editorial "Libro abierto" lo publicó El País el 13-02-2001 y su asunto principal es el Proyecto Genoma Humano (PGH) (v. Anexo).

\subsection{Lectura atenta y comprensiva: contextualización}

En el editorial se opina sobre un acontecimiento de actualidad científica: tras descifrar el GH, siete meses atrás, los científicos han acometido el siguiente paso: la "identificación de los genes" (contextualización informativa). La fecha de publicación indica que, a la sazón, gobernaba el PP por mayoría absoluta (contextualización sociopolítica).

Contenido cognoscitivo: en los tres primeros párrafos se exponen antecedentes para que el lector aprecie el valor que este hallazgo tiene para la investigación básica; pero, sobre todo, se remarca que, a pesar de que este conocimiento genético plantea nuevas paradojas que "mantendrán ocupados durante décadas a los investigadores básicos", "la medicina no tendrá que esperar tanto." Por tanto, se subraya el valor intrínseco del descubrimiento, los retos que deberá afrontar la investigación básica y, fundamentalmente, las inmediatas aplicaciones que tiene para la biomedicina.

El último párrafo representa un punto de inflexión, puesto que ahí se esbozan consecuentes, en forma de inquietantes escenarios futuros: el abuso que podrían cometer las aseguradoras y los efectos perniciosos que tendría que ese conocimiento deviniera en privado y fuera monopolio de unos pocos expertos. 


\subsection{Formulación de la tesis}

Aunque el 75\% del contenido del editorial (primeros tres párrafos) está dedicado al hallazgo científico y su relevancia, el editorial realmente se ha escrito para evidenciar las "dos reflexiones sociopolíticas" que se bosquejan en el último párrafo. Es aquí donde se plasma la tesis, que puede formularse así:

"Dado que el desciframiento del GH abre inquietantes escenarios futuros de uso y abuso del conocimiento genético, se hace imprescindible que los gobiernos regulen ciertas prácticas comerciales y fomenten la alfabetización científica entre los ciudadanos, para preservar así los derechos civiles."

\subsection{Estudio de los mecanismos argumentativos}

Aquí se estudian los distintos tipos de argumentos que el periódico despliega para defender su postura.

Aunque es propio de los argumentos de autoridad recurrir al testimonio de personajes de prestigio o expertos como prueba a favor de una idea o tesis (Perelman y Olbrechts-Tyteca, 1989: 470), puede observarse que los tres primeros párrafos remiten (implícitamente) a la autoridad de los investigadores involucrados en el PGH.

También se utilizan argumentos mediante el ejemplo, esto es, ejemplos significativos que pueden ser una generalización cuando "recurren a hechos concretos reales o ficticios que puedan aplicarse inductivamente a realidades generales" (MartínezCosta, 2010: 41). Véanse los dos ejemplos plausibles del último párrafo: las aseguradoras que pueden conculcar derechos ciudadanos y los expertos que pueden monopolizar el conocimiento en beneficio propio.

Los argumentos por analogía (establecer semejanzas a partir de las cuales se transfieren y asimilan características, afirmaciones o valores de una realidad a otra), también están presentes. Por ejemplo, la comparación entre el número de genes humanos y el del gusano permite inferir el largo y tortuoso camino que le queda a la ciencia básica por recorrer para llegar a explicaciones satisfactorias, puesto que la complejidad del ser humano no depende tanto del número de genes ("cifra inesperadamente baja") como de las interacciones de esos genes.

Los argumentos de causalidad también aparecen. Por ejemplo, dado que, según el editorial, pronto se dispondrá de "un conocimiento detallado de los riesgos sanitarios de cada persona", esos datos "se prestan a un evidente abuso por parte de las aseguradoras." Dadas estas premisas, la consecuencia lógica es que "los Gobiernos deben impulsar la legislación necesaria para evitar una personalización de las primas de seguros que acabe con el reparto equitativo del riesgo [...]."

\subsection{Identificación y justificación de la tipología del editorial y del juicio princi- pal del epílogo}

Tipología del editorial: el editorial realiza un análisis de la situación; en concreto, los antecedentes ayudan a mostrar la singularidad del conocimiento genético derivado del PGH, mientras que en el último párrafo se muestran dos plausibles consecuencias si tal conocimiento se empleara mal. Por tanto, nos encontramos en el grupo de los editoriales-AS. 
Si consideramos la tesis y la carga expresiva (v. Anexo), parece evidente que el editorial se ha escrito para perfilar las dos reflexiones sociopolíticas que, por una parte, advierten de potenciales riesgos para los ciudadanos y, por otra, apelan a la responsabilidad de los Gobiernos con fórmulas imperativas que expresan obligación: "deben impulsar", "deben hacer", "no deben quedar", "debe pasar." Con esto y sopesando los rasgos específicos de los tipos de editoriales-AS, es posible aventurar la siguiente hipótesis: el tipo principal es predictivo. Para confirmar o refutar esta hipótesis, es necesario identificar en el texto los rasgos específicos del predictivo (Santamaría y Casals, 2000: 276):

- Sobre la base del análisis situacional, diagnostica resultados de tipo social y político. Este es el rasgo más definitorio de este tipo de editoriales, y es precisamente lo que se hace en el último párrafo. Tras mostrar al lector la relevancia científica y social del desciframiento del genoma y la posterior identificación de los genes humanos, se esbozan dos inquietantes escenarios futuros que presentan implicaciones sociales y políticas. Como vimos, este diagnóstico es la razón de ser del editorial.

- Su función quiere ser referencial porque intenta persuadir de una verdad lógica, pero sobre todo es expresiva. En efecto, existe un apego a la realidad factual del $\mathrm{GH}$, pero el último párrafo expresa temores y advierte de peligros.

- Suelen cerrarse con juicios hipotéticos y sintéticos, también disyuntivos. El juicio principal del epílogo es sintético.

Además, "Libro abierto" es un editorial que tiene un importante componente didáctico, por lo que como tipo subsidiario se propone el explicativo. Veamos sus rasgos específicos (Ibid:: 274-275):

- Desde el principio manifiesta las presuntas causas de los hechos. Ya hemos estudiado que los tres primeros párrafos son de antecedentes.

- Relaciona los hechos entre sí en busca de los distintos motivos que los han podido favorecer. La importancia básica del conocimiento genético, la inminencia de sus aplicaciones clínicas y los amenazadores escenarios futuros, se derivan de las relaciones factuales que establece el editorial.

- Explicación casi pedagógica, porque pretende enseñar con argumentos instructivos de causas y consecuencias la naturaleza del acontecimiento y su transcendencia social. Este es, sin duda, el rasgo más destacado del explicativo. Todo editorial tiene explicaciones y no por ello es explicativo. Para considerar explicativo a un editorial hay que observar una clara vocación didáctico-divulgativa para hacer accesibles conocimientos que se presume serán difíciles de entender por un lector medio. Aquí, es notoria esta vocación: se usa la metáfora ("Libro abierto", letras químicas, etc.), la analogía (los genes humanos y los del gusano), la aclaración discursiva ("-el orden exacto de los 3.000 millones de bases o letras químicas que cada persona hereda de sus padres, y que contienen instrucciones básicas para construir un ser humano a partir de un simple óvulo fecundado-", refiriéndose al GH), la personificación ("Nuestra especie tiene que conformarse con 30.000 genes [...]"). 
- Juicio principal del epílogo: todo editorial está plagado de juicios. Pero nuestro afán será identificar y clasificar el juicio principal del epílogo, es decir, el juicio más destacado que se pretende sea asimilado por el lector. Obviamente, este juicio está parcial o totalmente entroncado con la tesis. El juicio principal es el siguiente: "La alfabetización científica de los ciudadanos debe pasar a ser parte de los fundamentos democráticos para que ellos puedan tomar las decisiones que les pertenecen." Este juicio es sintético, es decir, es un juicio a posteriori que se deriva de manera lógica del análisis previo. Como se aprecia, refleja en parte la tesis.

En resumen, el editorial presenta como tipo principal el predictivo y como tipo subsidiario el explicativo, esto es, es un híbrido predictivo-explicativo.

\subsection{Análisis del framing}

Dado que "Libro abierto" es un editorial cuyo asunto es tecnocientífico, se considera aquí una variante más ampliada de los cinco news frames expuestos en Neuman, Just y Crigler (1992) (v. epígrafe 3 y subepígrafe 4.4). En concreto, se trata de una tipología de encuadres adaptada de Gamson y Modigliani (1989) y usada en estudios sobre la cobertura mediática de la biotecnología (Nisbet y Lewenstein, 2002: 372; Priest y Eyck, 2003: 31-33; Reinhart, 2007: 8-9).

Si se analiza el editorial desde la perspectiva del framing, podemos establecer que el encuadre genérico más relevante es el de "Responsabilidad pública". Este frame se caracteriza por requerir control y participación públicos, abogar por mecanismos regulatorios y enfrentar intereses privados y públicos. En el último párrafo se apela a la responsabilidad que tienen los Gobiernos en impulsar una legislación que comporte un reparto equitativo del riesgo; así mismo, se apuesta por democratizar el conocimiento, esto es, por considerarlo un bien público y no privado.

En los tres primeros párrafos funciona el encuadre "Progreso", caracterizado por celebrar un descubrimiento, un nuevo desarrollo, apuntar la dirección que tomará este hallazgo cuando se aplique clínicamente y plantear el conflicto tácito entre ideas progresistas (en este caso, derechos de los ciudadanos y alfabetización científica de la población como fundamento de una sociedad democrática) e ideas conservadoras (liberalización del mercado, no injerencia del Estado).

En ocasiones, además, la construcción de determinados encuadres generales o específicos depende de la "apropiación social de conocimiento experto" que el periódico se arroga para defender (o atacar) ciertos postulados socio-políticos, en contextos locales concretos. La apropiación o utilidad social es la capacidad que tienen algunos conocimientos científicos de convertirse en un recurso para otros actores sociales ajenos a la comunidad científica (Zabala, 2004: 151). Como en otros editoriales de temática tecnocientífica (Alcíbar y Morales, en prensa), en "Libro abierto" se puede apreciar este fenómeno: el periódico utiliza el conocimiento sobre el genoma humano para sugerir turbadores escenarios futuros $\mathrm{y}$, de este modo, advertir de potenciales riesgos y apelar a los responsables políticos para que establezcan normativas que los minimicen y protejan los derechos de los ciudadanos. Puesto que el conocimiento científico se considera verdadero per se, objetivo y no sujeto a valores, los resultados de natu- 
raleza social y política que se vaticinan en el editorial, y que derivan de la singular naturaleza y relevancia del conocimiento genético aportado por los expertos, se vuelven automáticamente plausibles.

\subsection{Identificación y justificación de la ideología del medio}

Si el análisis previo se ha fundamentado bien, justificar la ideología del medio que subyace al editorial es una tarea relativamente sencilla. Aunque es habitual en el análisis de editoriales reducir la ideología a señalar las filias y fobias partidistas del periódico, no es así en este caso. Se hace imprescindible, por tanto, considerar la noción de ideología en un sentido lato. En efecto, el editorial no manifiesta preferencias o rechazos partidistas, pero presenta, como no puede ser de otra manera, una postura ideológica. El estudio de la tesis y del framing permite deducir que la ideología del periódico es progresista porque se alinea con el ciudadano y advierte de que si ciertos grupos de poder (aseguradoras y expertos) manipularan de forma incorrecta el conocimiento genético, podrían conculcar derechos civiles.

\subsection{Valoración general y otros datos complementarios de interés}

El equipo editorialista realiza un claro esfuerzo por mostrar la relevancia que para la investigación básica y, sobre todo, para la sociedad en su conjunto tiene el hecho de haber identificado los genes que componen el GH. Debido a su relevancia científica y social, los editorialistas vaticinan plausibles escenarios futuros en los que este conocimiento pudiera ser mal utilizado, conculcando así los derechos de los ciudadanos. Por tanto, el editorial tiene un claro valor intencional porque para los lectores de $E l$ País este texto continúa con el tono de vigilancia, de adalid de la democracia, de defensa de los derechos humanos y civiles que caracteriza a este periódico. Refleja un valor social de indignación ante los abusos del poder. Esta es una razón más que suficiente para que El País haya dedicado un editorial al asunto del PGH.

\section{Conclusiones}

El protocolo de análisis que se propone permite estudiar tanto la información explícita como la implícita en los editoriales periodísticos, desde una perspectiva pragmático-discursiva. La aplicación de una serie de pasos, no necesariamente secuenciales, posibilita al analista desentrañar los argumentos y las estrategias discursivas que los periódicos a través de sus editoriales despliegan para valorar acontecimientos de transcendencia social. Un concepto que aquí planteamos es el de "apropiación social de conocimiento experto", esto es, la capacidad que tienen ciertos conocimientos para convertirse en un recurso político para otros actores sociales ajenos a la comunidad científica. Esta apropiación es tanto más palmaria en aquellos editoriales que se derivan de noticias duras (hard news), como las económicas o científicas.

La combinación de herramientas del análisis del discurso y de la teoría del framing es la que arroja resultados interpretativos más fructíferos. Este procedimiento representa un esfuerzo sistemático por relacionar las elecciones lingüístico-retóricas que realiza el productor del texto con el contexto y la ideología, así como con las condiciones de interpretación de las audiencias. 


\section{Referencias bibliográficas}

ALCÍBAR, Miguel y MORALES, Beatriz (en prensa): "Framing biotechnology editorials: Expert knowledge appropriation in the Spanish media coverage".

BASSOLS, Margarida y TORRENT, Anna M. (2003): Modelos textuales. Teoría y práctica. Barcelona, Ediciones Octaedro.

BERINSKY, Adam J. y KINDER, Donald R. (2006): "Making sense of issues through media frames: Understanding the Kosovo crisis". The Journal of Politics, vol. 68, $\mathrm{n}^{\circ} 3$, pp. 640-656.

BROSSARD, Dominique (2010): "Framing and Priming in Science Communication", en PRIEST, Susanna Hornig (Ed.): Encyclopedia of Science and Technology Communication. Thousand Oaks, CA, Sage, pp. 310-313.

DAHINDEN, Urs (2002): "Biotechnology in Switzerland: Frames in a heated debate". Science Communication, vol. 24, $\mathrm{n}^{\circ}$ 2, pp. 184-197.

ENTMAN, Robert M. (2004): Projections of power. Framing news, public opinion, and U.S. foreign policy. Chicago, The University of Chicago Press.

ENTMAN, Robert M. (1993): "Framing: Toward clarification of a fractured paradigm". Journal of Communication, vol. 43, $\mathrm{n}^{\circ}$ 4, pp. 51-58.

ENTMAN, Robert M. (1991): "Framing U.S. coverage of international news: Contrasts in narratives of the KAL and Iran incidents". Journal of Communication, vol. $41, n^{\circ} 4$, pp. 6-27.

FAIRCLOUGH, Norman (1995): Critical discourse analysis: The critical study of language. London, Longman.

FAIRCLOUGH, Norman y WODAK, Ruth (2000): "Análisis crítico del discurso", en VAN DIJK, Teun A. (Comp.): El discurso como interacción social. Estudios sobre el discurso II: Una introducción multidisciplinaria. Barcelona, Gedisa, pp. 367-404.

FOX, Russell Arben (2011): "Progressivism", en KURIAN, George Thomas (Ed.): The Encyclopedia of Political Science. Washington, CQ Press, p. 1363.

GAMSON, William A. y MODIGLIANI, Andre (1989): "Media discourse and public opinion on nuclear power: A constructionist approach". American Journal of Sociology, vol. 95, $\mathrm{n}^{\circ} 1$, pp. 1-37.

HARDY, Cynthia (2001): "Researching organizational discourse". International Studies in Management and Organization, vol. 31, $\mathrm{n}^{\circ}$ 3, pp. 25-47.

HENRY, Francis \& TATOR, Carol (2002): Discourses of domination: Racial bias in the Canadian English-language press. Toronto, University of Toronto Press.

LE, Elisabeth (2009): "Editorial's genre and media roles: Le Monde's editorials from 1999 to 2001". Journal of Pragmatics, vol. 41, pp. 1727-1748.

MARTÍNEZ-COSTA, María del Pilar (2010): "Estrategias argumentativas en el comentario radiofónico", en MARTÍNEZ PASAMAR, Concepción (Ed.): Estrategias argumentativas en el discurso periodístico. Frankfurt, Peter Lang, pp. 31-50. 
NEUMAN, W. Russell; JUST, Marion R. \& Crigler, Ann N. (1992): Common Knowledge. News and the Construction of Political Meaning. Chicago, The University Chicago Press.

NISBET, Matthew C. \& LEWENSTEIN, Bruce V. (2002): "Biotechnology and the American media: The policy process and the elite press, 1970 to 1999". Science Communication, vol. 23, no 4, pp. 359-391.

PERELMAN, Chaïm y OLBRECHTS-TYTECA, Lucie (1989): Tratado de la Argumentación. La Nueva Retórica. Madrid, Gredos.

PHILLIPS, Nelson \& HARDY, Cynthia (2002): Discourse analysis: Investigating processes of social construction. Thousand Oaks, CA, Sage.

PRIEST, Susanna Hornig \& EYCK, Toby Ten (2003): "News coverage of biotechnology debates". Society, vol. 40, n⿳ 6, pp. 29-34.

REINHART, Hannah C. (2007): "Framing the Biotechnology Debate: A Textual Analysis of Editorials and Letters to the Editor in the St. Louis Post-Dispatch", Global Media Journal, vol. 6, nº 10, pp. 1-19.

SÁDABA, Teresa (2008): Framing: el encuadre de las noticias. Buenos Aires, La Crujía Ediciones.

SANTAMARÍA, Luisa (1997): Géneros para la Persuasión en Periodismo. Madrid, Editorial Fragua.

SANTAMARÍA, Luisa y CASALS, María Jesús (2000): La opinión periodistica. Argumentos y géneros para la persuasión. Madrid, Editorial Fragua.

SHAH, Dhavan V., WATTS, Mark D., DOMKE, David, \& FAN, David P. (2002): "News framing and cueing of issue regimes. Explaining Clinton's public approval in spite of scandal", Public Opinion Quarterly, 66, pp. 339-370.

SEMETKO, Holli A. \& VALKENBURG, Patti M. (2000): "Framing European politics: a content analysis of press and television news", Journal of Communication, vol. 50, nº. 2, pp. 93-109.

TANKARD, James W. (2001): "The empirical approach to the study of media framing”, en REESE, Stephen D., GANDY, Oscar H., and GRANT, August E. (Eds.): Framing Public Life. Perspectives on Media and our Understanding of the Social World. Mahwah, NJ, Lawrence Erlbaum.

VAN DIJK, Teun A. (2009): Society and discourse: how social contexts influence text and talk. Cambridge, Cambridge University Press.

VAN DIJK, Teun A. (2000a): "El estudio del discurso", en VAN DIJK, Teun A. (Comp.): El discurso estructura y proceso. Estudios sobre el discurso I: Una introducción multidisciplinaria. Barcelona, Gedisa.

VAN DIJK, Teun A. (2000b): "El discurso como interacción en la sociedad", en VAN DIJK, Teun A. (Comp.): El discurso como interacción social. Estudios sobre el discurso II: Una introducción multidisciplinaria. Barcelona, Gedisa. 
VAN DIJK, Teun A. (1999): Ideología. Una aproximación multidisciplinaria. Barcelona, Gedisa.

VAN DIJK, Teun A. (Ed.) (1997): Discourse as Social Interaction. London, Sage.

VAN DIJK, Teun A. (1990): La noticia como discurso. Barcelona, Paidós Comunicación.

VREESE, Claes H. de; PETER, Joechen; \& SEMETKO, Holli A. (2001): "Framing politics at the launch of the euro: A cross-national comparative study of frames in the news". Political Communication, vol. 18, n 2, pp. 107-122.

ZABALA, Juan Pablo (2004): "La utilidad social de los conocimientos científicos como problema sociológico", en KREIMER, Pablo, THOMAS, Hernán y otros: Producción y uso social de conocimientos. Estudios de sociología de la ciencia y la tecnología en América Latina. Buenos Aires, Universidad Nacional de Quilmes, pp. 151-172.

\section{Anexo}

\section{Libro abierto}

\section{(El País, 13-02-2001)}

Siete meses después de la lectura completa del genoma humano -el orden exacto de los 3.000 millones de bases o letras químicas que cada persona hereda de sus padres, y que contienen las instrucciones básicas para construir un ser humano a partir de un simple óvulo fecundado-, los científicos han culminado el siguiente paso en la comprensión de esa mareante cantidad de información: la identificación de los genes, o unidades básicas de sentido, en ese inmenso texto escrito en el críptico lenguaje del ADN. El resultado ha sido una sorpresa científica, pero al mismo tiempo ha puesto a tiro de piedra las primeras aplicaciones clínicas de lo que sin duda alguna constituirá la gran revolución de la medicina en las próximas décadas.

Nuestra especie tiene que conformarse con 30.000 genes, una cifra inesperadamente baja, cuando el más modesto de los gusanos tiene 19.000 genes. Con sólo un tercio más de genes, el embrión humano en desarrollo tiene que construir un cerebro 300 millones de veces más complejo que el del gusano. Nuestra singularidad como especie está en los genes -no otra cosa distingue el óvulo humano del de una rata-, pero es obvio que a la ciencia genética aún le queda mucho trabajo por hacer para lograr explicaciones completas.

El genoma humano se ha revelado también como un gran derrochador de espacio. El 95\% del genoma parecen textos absurdos, a veces ruinas de antiguos genes de virus, largos tramos de ADN que parecen haberse acumulado allí sólo porque no estorban demasiado. Estas paradojas mantendrán ocupados durante décadas a los investigadores básicos. Pero la medicina no tendrá que esperar tanto. Las técnicas necesarias para examinar de un golpe la totalidad de los genes de un individuo están ya listas y las aplicaciones de esta metodología -independientemente de cuánto tarden en ofrecerse a los ciudadanos- son potencialmente inmediatas. 
El análisis del genoma merece dos reflexiones sociopolíticas. La primera es que las técnicas genómicas van a permitir muy pronto un conocimiento detallado de los riesgos sanitarios de cada persona, y que esos datos se prestan a un evidente abuso por parte de las aseguradoras. Los Gobiernos deben impulsar la legislación necesaria para evitar una personalización de las primas de seguros que acabe con el reparto equitativo del riesgo, y lo deben hacer cuanto antes. La segunda es que la cascada de medidas políticas sobre privacidad y sanidad que las técnicas genómicas están a punto de provocar no deben [sic] quedar en manos de los pocos expertos capaces de entender la ciencia que subyace en ellas. La alfabetización científica de los ciudadanos debe pasar a ser parte de los fundamentos democráticos para que ellos mismos puedan tomar las decisiones que les pertenecen.

NOTA: El subrayado hace referencia a palabras o expresiones con carga valorativa. 